\section{THU0074 BODY MASS INDEX IN EARLY RHEUMATOID ARTHRITIS IN UNDERWEIGHT PATIENTS IS ASSOCIATED WITH MORE PROGRESSION OF EROSIONS OVER 15 YEARS AND IN OBESE PATIENTS WITH LESS PROGRESSION OF JOINT SPACE NARROWING}

S. Ajeganova ${ }^{1}$, K. Forslind ${ }^{2}$, B. Svensson ${ }^{2}$, I. Hafström ${ }^{1} \cdot{ }^{1}$ Department of Medicine Huddinge, Karolinska Instiutet, Stockholm; ${ }^{2}$ Department of Clinical Sciences, Lund University, Lund, Sweden

Background: Previous short-term follow-up studies and subanalyses of clinical trials in rheumatoid arthritis (RA) have suggested that low body mass index (BMI) is associated with more radiographic joint progression and high BMI with less. The effect of BMI on progression of erosion score (ES) and joint space narrowing (JSN) could be different in underweight and obese patients.

Objectives: To investigate the association between BMI in early RA with radiographic damage during 15 years; to examine if known predictors of a worse radiographic outcome could explain differential radiographic outcome in low and high BMl groups.

Methods: Four hundred and seventy-three patients from the BARFOT study included from 1992 to 1999 who performed their 15-year assessment were studied. The patients were assessed at inclusion and after 1, 2, 5, 8 and 15 years. The groups were defined by BMI $\left(\mathrm{kg} / \mathrm{m}^{2}\right)$ at inclusion: $\mathrm{BMI} \leq 20,(\mathrm{n}=27)$, BMI $20<25(n=210)$, BMI $25<30(n=179)$, and BMI $\geq 30(n=57)$. X-rays of hands and feet were scored by the Sharp-van der Heijde scoring method (SHS). Linear mixed models with SHS, ESR, CRP, SJC and TJC as outcome, and BMI at inclusion as predictor was used, adjusted for age, sex, initial treatment, ACPA and smoking.

Results: At baseline, total score of SHS, ES and JSN did not differ between $\mathrm{BMI}$ groups. There were more women and smokers in $\mathrm{BMI}<20$ group and older patients in $\mathrm{BMI} \geq 30$ group. The baseline disease characteristics were similar in the BMI groups.

For the patients with $\mathrm{BMI} \leq 20$ at inclusion, $\mathrm{BMI}$ was associated with a higher predicted SHS progression during follow-up, effect size 5.11 (95\% Cl 1.72 to 15.15) $\mathrm{p}=0.005$, while for the patients with $\mathrm{BMI} \geq 30$ at inclusion, $\mathrm{BMI}$ was associated with lower SHS, effect size $0.92(0.86$ to 0.99$) p=0.028$. The directions of association between BMI at inclusion and ES and JSN were similar to that for the total SHS. The effect size of the association with erosion progression was however significant only in the $\mathrm{BMl}<20$ group, 1.15 (2.72 to 6.42 ) $\mathrm{p}=0.025$ (in the $B M l \geq 30$ group $0.95(0.90-1.00) p=0.074)$. On the other hand, association between $\mathrm{BMI}$ and JSN progression was significant only in the $\mathrm{BMI} \geq 30$ group, 0.93 (0.87 to 0.99 ) $\mathrm{p}=0.033$ (in the $\mathrm{BMl}<20$ group $2.53(0.83-7.67) \mathrm{p}=0.096)$.

There were no associations between BMI and radiographic damage in BMI $20<25$ and BMI $25<30$ groups.

We found no significant association between BMI and ESR, CRP, SJC, TJC over time in the $\mathrm{BMI} \leq 20$ group. In the $\mathrm{BMI} \geq 30$ group, $\mathrm{BMI}$ was associated with a higher predicted CRP during follow-up, effect size 1.06 (1.01 to 1.12) $p=0.028$, but not with ESR and SJC. Compared to the patients with BMI 20-25, patients with $B M I \geq 30$ had higher TJC over 15 years, 3.17 (1.06 to 9.27) $p=0.038$.

Conclusions: Underweight at onset of RA is associated with more radiographic damage up to 15 years and obesity with less joint damage, independent of sex, ACPA and smoking status. The effect of BMI is not explained by measures of disease activity.

Disclosure of Interest: None declared

DOI: 10.1136/annrheumdis-2017-eular.4141

\section{THU0075 THE RELATIONSHIP BETWEEN DISEASE ACTIVITY AND DISABILITY IS MEDIATED BY PAIN AND FATIGUE IN EARLY RHEUMATOID ARTHRITIS}

S. Twigg ${ }^{1,2}$, E.M.A. Hensor ${ }^{1}$, P. Emery ${ }^{1}$, A.W. Morgan ${ }^{1}$, A. Tennant ${ }^{3}$ on behalf of Yorkshire Early Arthritis Register. ${ }^{1}$ Leeds Institute Rheumatic and Musculoskeletal Medicine, University of Leeds: ${ }^{2}$ National Institute for Health Research-Leeds Musculoskeletal Biomedical Research Unit, Leeds Teaching Hospitals NHS Trust, Leeds, United Kingdom; ${ }^{3}$ Swiss Paraplegic Research, Nottwil, Switzerland

Background: Disability in early rheumatoid arthritis (RA) is correlated with disease activity. However, the relationship between these two clinical outcomes is relatively under-investigated. Understanding how disability is driven by disease activity will allow targeted interventions to improve function in early RA, alongside the suppression of inflammation.

Objectives: To identify mediators in the relationship between disease activity and disability in early RA.

Methods: Cases with new consultant-made diagnoses of RA were recruited to Yorkshire Early Arthritis Register within 24 months of symptom onset. At the baseline assessment, clinical variables were collected including the 3 variable disease activity score from counts of 28 tender and swollen joints and C-reactive protein (DAS28), Health Assessment Questionnaire (HAQ) and visual analogue scores (VAS) of pain and fatigue. Structural equation models (SEM) were constructed to evaluate the relationship between DAS28, HAQ, pain, symptom duration (SD), age and fatigue.

Results: Of 721 cases included, 482 were female and 239 male. Median age was 58 for both genders and median HAQ was 1.25 and 1.00 for women and men, respectively. A path model within a SEM framework (Figure 1) was a good fit to the data (Chi square 7.528, $\mathrm{df}=6, \mathrm{p}=0.2748$; CFI 0.997; RMSEA 0.027). However, the model could not be applied simultaneously to both genders; although estimates of regression coefficients did not vary between males and females (metric invariance), model intercepts were different. In earlier models, age was not a significant predictor and regressions of fatigue on DAS28 were not significant: the effect of DAS28 upon fatigue was fully mediated by pain. Standardised coefficients of direct and indirect effects of DAS28 on HAQ are shown in Table 1, together with Sobel tests for significance of mediator variables. The greatest effect upon HAQ was the direct effect from DAS28, but some of the effect of DAS28 on HAQ was partially mediated by pain. Furthermore, the effect of pain upon $\mathrm{HAQ}$ was also partially mediated through fatigue. According to the Sobel test, pain and fatigue were significant mediators in both females and males.

Table 1 Total, Direct and Indirect effects upon HAQ

\begin{tabular}{lcccccccc}
\hline Standardised effect upon HAQ & \multicolumn{3}{c}{ Females } & & \multicolumn{3}{c}{ Males } \\
\cline { 2 - 3 } & Estimate & SE & $\mathrm{p}$ & & Estimate & SE & $\mathrm{p}$ \\
\hline DAS28 total & 0.412 & 0.040 & $<0.001$ & & 0.508 & 0.053 & $<0.001$ \\
DAS28 indirect & 0.139 & 0.024 & $<0.001$ & & 0.163 & 0.033 & $<0.001$ \\
DAS28- direct & 0.282 & 0.046 & $<0.001$ & & 0.344 & 0.060 & $<0.001$ \\
DAS28 via pain and fatigue & 0.038 & 0.010 & $<0.001$ & & 0.032 & 0.014 & 0.025 \\
DAS28 via pain & 0.101 & 0.024 & $<0.001$ & & 0.131 & 0.033 & $<0.001$ \\
Sobel test statistic (fatigue via pain) & 3.280 & 0.002 & 0.001 & & 2.279 & 0.002 & 0.022 \\
Sobel test statistic (Pain) & 3.920 & 0.085 & $<0.001$ & & 3.253 & 0.122 & 0.001
\end{tabular}

SE, standard error.

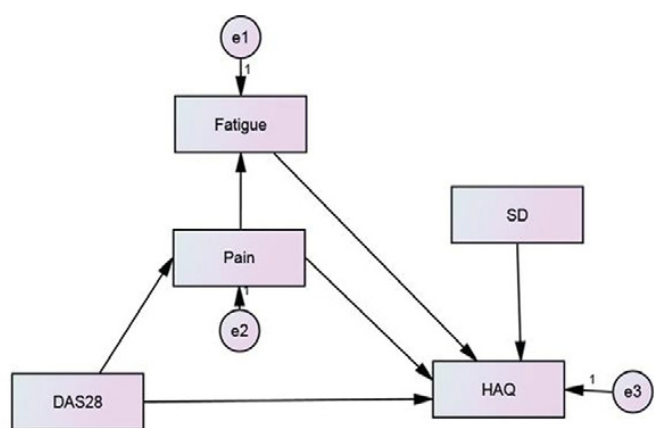

Figure 1. Path diagram to show the relationship between disease activity and disability mediated by pain and fatigue.

SD, symptom duration; e1-3, error terms (representing the unexplained variance in outcomes)

Conclusions: DAS28 dominates the impact upon HAQ in early RA; pain is shown to be an important mediator of the effects of DAS28 on $\mathrm{HAQ}$, while fatigue is important as a mediator of the effect of pain on $\mathrm{HAQ}$. This adds to previous evidence that pain is a driver of fatigue in RA (1) and suggests that interventions to manage pain could be important adjuncts to supression of inflammation in early RA, in order to optimise function.

References:

[1] Druce KL, Jones GT, Macfarlane GJ, Basu N. (2015) Arthritis \& Rheumatology, 67: 2303.

Disclosure of Interest: None declared

DOI: 10.1136/annrheumdis-2017-eular.6152

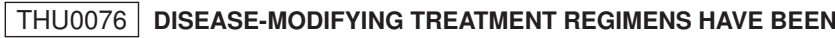 INSUFFICIENT TO REDUCE THE INCIDENCE OF SYSTEMIC AA AMYLOIDOSIS ASSOCIATED WITH RHEUMATOID ARTHRITIS IN CONTRAST TO A SIGNIFICANT REDUCTION IN THOSE WITH JUVENILE IDIOPATHIC ARTHRITIS}

T.A.-B. Youngstein ${ }^{1}$, T. Lane ${ }^{1}$, J. Gilbertson ${ }^{1}$, J. Pinney ${ }^{1}$, T. Rezk ${ }^{1}$, R. Manwani ${ }^{1}$, C.C. Quarta ${ }^{1}$, A. Wechalekar ${ }^{1}$, S. Mahmood ${ }^{1}$, S. Sachchithanantham ${ }^{2}$, M. Fontana ${ }^{1}$, C. Whelan ${ }^{1}$, J.D. Gillmore ${ }^{3}$, P.N. Hawkins ${ }^{1}$, H.J. Lachmann ${ }^{1}$. ${ }^{1}$ National Amyloidosis Centre, UCL Division of Medicine; ${ }^{2}$ National Amyloidosis Centre, UCL Division of Medicine, London; ${ }^{3}$ National Amyloidosis Centre, National Amyloidosis Centre, UCL Division of Medicine, London, London, United Kingdom

Background: The UK National Amyloidosis Centre has the largest known cohort of individuals with AA amyloidosis, with 660 cases since 1990. A third present in end stage renal failure (33\%), with a median survival of 133 months from diagnosis ${ }^{1}$. Over 27 years the rate of new cases has remained remarkably constant with a median of 24 diagnoses per annum (IQR 18.5-30.5) but responsible for a decreasing proportion of new cases of systemic amyloidosis from $35 \%$ in the first 5 years to $6 \%$ in the last 5 years of the cohort.

Objectives: We sought to determine to what extent advances in treatment of the inflammatory arthritides have influenced the aetiology of AA Amyloidosis over time.

Methods: Retrospective analysis of the UK National Amyloidosis Centre AA 
Amyloidosis database containing baseline demographic and clinical data. Data was analysed using a Chi-squared test (GraphPad Prism 7.0).

Results: Between 1990-2000 there were 188 new cases of AA Amyloidosis of which $51(27.1 \%)$ had an underlying diagnosis of rheumatoid arthritis (RA), median age at diagnosis of amyloid was 60 years. $37(19.7 \%)$ had a diagnosis of Juvenile Idiopathic Arthritis (JIA), median age 29 years. Between 2007 and 2017 there were 270 new diagnoses of AA Amyloidosis, of whom 57 had RA (21.1\%), median age 66 years, and $5(1.9 \%)$ had JIA, median age 37 years. Since the widespread use of combination disease-modifying and biologic therapy there has been a significant reduction in the incidence of JIA-associated AA Amyloidosis $(p<0.0001)$. In contrast, the incidence of RA-associated AA Amyloidosis is unchanged $(\mathrm{p}<0.1357)$

Conclusions: Advances in the treatment of JIA have significantly reduced the incidence of AA Amyloidosis in this cohort. In contrast, despite largely the same medication and similar treatment targets, RA continues to be responsible for a substantial proportion of new cases of AA Amyloidosis. One possible explanation for this may be that current assessment of disease activity in RA is sufficient to identify those at risk of joint damage or radiological progression of disease but insufficient for identifying peristent subclinical biochemical inflammation. One approach for reducing this risk may be the routine measure of the AA Amyloid precursor protein, serum Amyloid A protein (SAA) in those with RA, as it is well established that levels of SAA of below $10 \mathrm{mg} / \mathrm{L}$ prevents the accumulation of $A A$ Amyloid in those with inflammatory disease.

[1] Lachmann, H. J., Goodman HJ, Gilbertson JA, Gallimore JR, Sabin CA, Gillmore JD, Hawkins PN (2007). Natural history and outcome in systemic AA amyloidosis. N Engl J Med 356(23): 2361-2371.

Disclosure of Interest: None declared

DOI: 10.1136/annrheumdis-2017-eular.5005

\section{THU0077 ANTI-COLLAGEN TYPE II ANTIBODIES ARE ASSOCIATED WITH AN ACUTE ONSET RHEUMATOID ARTHRITIS PHENOTYPE AND PROGNOSTICATE LOWER DEGREE OF INFLAMMATION}

V.A. Manivel ${ }^{1}$, M. Mullazehi ${ }^{1}$, L. Padyukov ${ }^{2}$, H. Westerlind $^{3}$, L. Klareskog ${ }^{2}$, L. Alfredsson ${ }^{3}, \mathrm{~S}$. Saevarsdottir ${ }^{2}$, J. Rönnelid ${ }^{1} .{ }^{1}$ Immunology genetics and Pathology, Uppsala University, Uppsala; ${ }^{2}$ Rheumatology Unit, Department of Medicine, Karolinska University Hospital and Karolinska Institutet; ${ }^{3}$ Institute of Environmental Medicine, Karolinska Institutet, Stockholm, Sweden

Background: Anti-collagen II antibody (anti-CII) positive RA patients present with early but not persistent signs of inflammation and joint erosions. This early antiCll-dependent phenotype coincides with high anti-Cll levels around the time of RA diagnosis, whereafter anti-CII levels drop. Our previous studies showed that this phenotype is associated with in vitro cytokine production by monocytes, activation of granulocytes, and enhanced chemokine production by monocyte/granulocyte cocultures, stimulated with anti-CII containing immune complexes. These in vitro findings argue that elevated anti-CIl levels at time of RA diagnosis are functionally related to the corresponding acute onset RA phenotype.

Objectives: Our previous comparison done in a small RA cohort $(n=274)$ describe that anti-cyclic citrullinated peptide 2 (anti-CCP2) positive patients have a severe long-term prognosis but anti-Cll positive patients have transient inflammation. In the present study we wanted to extend this in a large RA cohort with clinical follow-up data, and to relate to HLA-DRB1* alleles.

Methods: Anti-CII and anti-CCP2 were measured at baseline in 773 patients from the Swedish Epidemiological Investigations in Rheumatoid Arthritis (EIRA) study with clinical follow-up data from the Swedish Rheumatology Quality (SRQ) registry, and 1476 patients with HLA-DRB1* information. Comparisons were done concerning CRP, ESR, TJC, SJC, DAS28, DAS28CRP, pain-VAS, global-VAS and $\mathrm{HAQ}$ at 8 occasions during 5 years, and association to HLA-DRB1* alleles.

Results: Anti-Cll was detected in 6.6\% (97/1476), and anti-CCP2 in 57.9\% $(855 / 1476)$ of the patients. There was no significant difference in treatment strategy at diagnosis for patients with and without those antibodies. Anti-Cll associated with elevated CRP, ESR, SJC, DAS28 and DAS28CRP at diagnosis and up to six months, whereas anti-CCP2 associated with SJC and DAS28 from 6 months to 5 years, but not earlier. The anti-Cll-associated phenotype was strong, and predominated also in anti-CII/anti-CCP2 double positive patients. Compared to baseline levels, anti-CII was asscociated with improvements in CRP, ESR, SJC, TJC and DAS28 over time, whereas anti-CCP2 was associated with deteriorations in SJC and DAS28 over time, compared to antibody negative patients. Anti-CII positive patients achieved EULAR good or moderate response more often than negative patients whereas the opposite was found for anti-CCP2 positive patients (figure). Anti-Cll was positively associated with HLADRB $1{ }^{*} 01$ and HLADRB $1{ }^{*} 03$, with significant interaction, and double positive individuals had $>14$ times higher mean anti-CII levels than HLA double negatives. Whereas smoking associated with elevated anti-CCP2 levels, smokers has lower anti-CII levels.

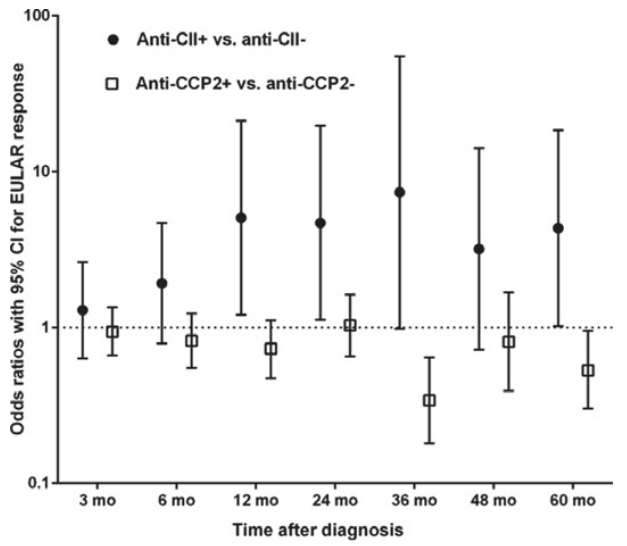

Conclusions: Anti-Cll seropositive RA represents a distinct phenotype, in many respects representing the converse to the clinical, genetic and smoking associations described for ACPA. Although not diagnostically useful, early anti-CII determinations predict favourable inflammatory outcome in RA. The combined analysis of anti-CII and ACPA/anti-CCP2 may be a new two-dimensional tool for predicting the prognosis and chosing therapy in newly diagnosed RA patients.

Disclosure of Interest: None declared

DOI: 10.1136/annrheumdis-2017-eular.2776

\section{THU0078 CONCOMITANT USE OF CONVENTIONAL SYNTHETIC DMARDS AND RESPONSE TO BARICITINIB}

A. Kavanaugh ${ }^{1}$, C. Helt ${ }^{2}$, D. Muram ${ }^{2}$, J. Alam ${ }^{2}$, V. Arora ${ }^{2}$, A.L. Pinto Correia ${ }^{2}$, I. de la Torre ${ }^{2}$, R. van Vollenhoven ${ }^{3}$. ${ }^{1}$ UC San Diego School of Medicine, la Jolla; ${ }^{2}$ Eli Lilly and Company, Indianapolis, United States; ${ }^{3}$ Amsterdam Rheumatology \& Immunol Center, Amsterdam, Netherlands

Background: Baricitinib (BARI), an oral JAK1/JAK2 inhibitor, is in development for patients (pts) with moderate to severe rheumatoid arthritis (RA)..$^{1,2}$

Objectives: This post-hoc analysis of two phase 3 studies assessed whether concomitant use of conventional synthetic disease-modifying antirheumatic drugs (csDMARDs) altered the response or safety outcomes to BARI in RA pts and evaluated the effect of concomitant corticosteroid use on the efficacy of BARI.

Methods: Pts with $\geq 6$ swollen and tender joints and no prior biologic DMARD use were enrolled. In RA-BEAM (NCT01710358), methotrexate (MTX)-inadequate responder (IR) pts were randomised to PBO once daily (QD), BARI $4 \mathrm{mg} Q D$, or adalimumab $40 \mathrm{mg}$ biweekly. ${ }^{1}$ In RA-BUILD (NCT01710358), csDMARD-IR pts were randomised to placebo (PBO) or BARI (2 or $4 \mathrm{mg}) \mathrm{QD}^{2}$ Pts continued background csDMARD (including MTX) therapy. This post-hoc analysis included the PBO $(\mathrm{N}=716)$ and BARI $4 \mathrm{mg}(\mathrm{N}=714)$ pts and assessed the number and type of concomitant csDMARDS and concurrent corticosteroid use.

Results: $71 \%, 21 \%$, and $6 \%$ of PBO pts were taking MTX alone, MTX + $\geq 1$ other csDMARD, and non-MTX csDMARDs, respectively; in BARI $4 \mathrm{mg}$ pts, the

Abstract THU0078 - Table 1. Efficacy and Safety Through 12 Weeks Based on Concomitant csDMARD Usage

\begin{tabular}{|c|c|c|c|c|c|c|}
\hline & \multicolumn{3}{|c|}{ Placebo $(\mathrm{N}=716)$} & \multicolumn{3}{|c|}{ Baricitinib $4 \mathrm{mg}(\mathrm{N}=714)$} \\
\hline & $\begin{array}{c}\text { MTX Alone } \\
(\mathrm{n}=506)\end{array}$ & $\begin{array}{c}\text { MTX }+\underset{(n=147)}{\geq 1 \text { csDMARDs }} \\
(n=140\end{array}$ & $\begin{array}{c}\text { Non-MTX csDMARDs } \\
(n=43)\end{array}$ & $\begin{array}{l}\text { MTX Alone }(n=527) \\
(n=527)\end{array}$ & $\begin{array}{c}\text { MTX }+\underset{(n=131)}{\geq 1 \text { csDMARDs }} \\
(n=1\end{array}$ & $\begin{array}{c}\text { Non-MTX csDMARDs } \\
(\mathrm{n}=42)\end{array}$ \\
\hline \multicolumn{7}{|l|}{ Efficacy measures } \\
\hline ACR20 & $210(42)$ & $57(39)$ & $17(40)$ & $361(69)$ & $85(65)$ & $25(60)$ \\
\hline ACR50 & $84(17)$ & $18(12)$ & $7(16)$ & $227(43)$ & $52(40)$ & $13(31)$ \\
\hline ACR70 & $20(4)$ & $7(5)$ & $3(7)$ & $106(20)$ & $19(15)$ & $5(12)$ \\
\hline $\mathrm{SDAl} \leq 11$ & $92(18)$ & $18(12)$ & $10(23)$ & $221(42)$ & $45(34)$ & $14(33)$ \\
\hline SDAI $\leq 3.3$ & $8(2)$ & $3(2)$ & 0 & $52(10)$ & $4(3)$ & $2(5)$ \\
\hline DAS28-ESR $\leq 3.2$ & $11(2)$ & $3(2)$ & $1(2)$ & $58(11)$ & $11(8)$ & $2(5)$ \\
\hline DAS28-ESR $<2.6$ & $35(7)$ & $10(7)$ & $4(9)$ & $129(24)$ & $27(21)$ & $7(17)$ \\
\hline \multicolumn{7}{|l|}{ Safety measures } \\
\hline$\geq 1$ adverse event & $442(87)$ & $132(90)$ & 39 (91) & $465(88)$ & $116(89)$ & $40(95)$ \\
\hline$\geq 1$ serious adverse event & $14(3)$ & $4(3)$ & $3(7)$ & $14(3)$ & $1(1)$ & $1(2)$ \\
\hline Discontinuation due to adverse event & $16(3)$ & $2(1)$ & 0 & $11(2)$ & $5(4)$ & $3(7)$ \\
\hline Death & $1(0.2)$ & $1(0.7)$ & 0 & 0 & 0 & 0 \\
\hline
\end{tabular}

Data are $\mathrm{n}(\%)$ 